\title{
La impronta del ethos inquisitorial en la defensa especializada en adolescentes en el modelo acusatorio*
}

\author{
The Imprint of the Inquisitorial Ethos in the Defense Specialized in \\ Adolescents in the Accusatory Model \\ A marca do ethos inquisitorial na defesa especializada em adolescentes \\ no modelo acusatório
}

GuAdALUPe Irene JUÁREZ OrTiz

FECHA DE RECEPCIÓN: 16 DE ENERO DE 2019. FECHA DE APROBACIÓN: 5 DE ABRIL DE 2019

Doi: http://dx.doi.org/10.12804/revistas.urosario.edu.co/sociojuridicos/a.7834

Para citar: Juárez Ortiz, G.I. (2019). La impronta del ethos inquisitorial en la defensa especializada en adolescentes en el modelo acusatorio. Revista Socio-Jurídico 21(2), 51-72. Doi: http://dx.doi.org/10.12804/revistas. urosario.edu.co/sociojuridicos/a.7834

\section{RESUMEN}

El presente texto tiene como objetivo analizar el papel que la defensoría pública desempeña dentro del Sistema Integral de Justicia para Adolescentes desde un enfoque antropológico, que contribuya a comprender cuál es la relación que dicha institución guarda con la cultura jurídica en la cual nuestro país se inscribe. De manera específica, el argumento central consiste en que para operar de manera efectiva la defensa pública dentro del sistema penal acusatorio no solo se requiere que goce de autonomía institucional, sino que, como institución oficial, reconozca y modifique la impronta del ethos inquisitorial

* El presente texto fue elaborado con datos obtenidos durante la estancia posdoctoral en la UNAM en el Programa de Becas Posdoctorales, como becaria del Instituto de Investigaciones Jurídicas entre septiembre de 2016 y enero de 2018. Los datos aquí expuestos fueron recabados mediante trabajo de campo de corte etnográfico en los estados de Morelos y Querétaro.

** Doctora y maestra en Antropología Social por el Centro de Investigaciones y Estudios Superiores en Antropología Social (CIESAS). Licenciada en Antropología Social por la Universidad Veracruzana (UV). Integrante del Sistema Nacional de Investigadores (SNI-CONACYT). Es Presidenta del Comité Internacional del Foro Latinoamericano de Antropología del Derecho (FLAD) y Coordinadora de la sede México del mismo. Se desempeña como profesora titular del Proyecto de Investigación Formativa en Antropología del Derecho de la Escuela Nacional de Antropología e Historia (ENAH) y como Investigadora Titular del Instituto Nacional de Ciencias Penales (INACIPE).

Correo electrónico: lirenejo@hotmail.com 
que el Estado mexicano ha establecido históricamente en la relación con las personas menores de edad acusadas de infringir la ley y de la cual, como institución estatal, continúa abrevando.

Palabras clave: justicia para adolescentes, defensoría pública, reforma judicial, cultura judicial.

\section{ABSTRACT}

The purpose of this text is to analyze the role that the public defender plays specifically within the Integral System of Justice for Adolescents from an anthropological perspective, which will help to understand the relationship that this institution has with the legal culture in which our country sign up. The central argument is that in order to effectively operate public defense within the accusatory criminal system not only are they required to enjoy institutional autonomy, but to recognize and modify the imprint of the inquisitorial ethos that the Mexican State has historically established in the relationship with minors accused of breaking the law, which they continue to water.

Keywords: Justice for teenagers, public defender, judicial reform, judicial culture.

\section{RESUMO}

O presente texto tem como objetivo analisar o papel que a defensoria pública desempenha dentro do Sistema Integral de Justiça para Adolescentes desde um enfoque antropológico, que contribua a compreender qual é a relação que dita instituição guarda com a cultura jurídica na qual nosso país inscreve-se. De maneira específica, o argumento central consiste em que para operar de forma efetiva a defesa pública dentro do sistema penal acusatório não só requer-se que goze de autonomia institucional, mas que, como instituição oficial, reconheça e modifique a marca do ethos inquisitorial que o Estado mexicano tem estabelecido historicamente na relação com as pessoas menores de idade acusadas de infringir a lei e da qual, como instituição estatal, continua abrevando.

Palavras-chave: justiça para adolescentes, defensoria pública, reforma judicial, cultura judicial. 
En México, la introducción del modelo penal acusatorio en 2008 ha permitido un mayor protagonismo de la Defensoría Pública. En el sistema penal de adultos, los artículos 17 y 20 de la Constitución Federal establecen la obligatoriedad de que el Estado brinde a las personas imputadas una defensa pública, así como las características que ésta debe tener. ${ }^{1}$ En materia de adolescentes, el artículo 18 de la Carta Magna, ${ }^{2}$ así como la Ley Nacional del Sistema Integral de Justicia Penal para Adolescentes (en adelante LNSIJPA), ${ }^{3}$ establecen que los defensores que asistan a las personas adolescentes en los procesos penales deberán estar especializados. ${ }^{4}$

No obstante, pocos son los estudios que se han centrado en analizar el papel que esta institución desempeña actualmente en nuestro país en el sistema penal de adultos (Esquinca, 2006; Magaloni \& Ibarra, 2008; Mendoza \& Ávila, 2009, Fix-Fierro \& Abad, 2015, 2016). Dentro de estos, por plantear una aproximación a partir de la sociología jurídica y del enfoque comparativo y de datos empíricos que permite a los autores mostrar el complejo escenario que las Defensorías Públicas enfrentan en

$1 \quad$ El art. 17 plantea: “La Federación y las entidades federativas garantizarán la existencia de un servicio de defensoría pública de calidad para la población y asegurarán las condiciones para un servicio profesional de carrera para los defensores. Las percepciones de los defensores no podrán ser inferiores a las que correspondan a los agentes del Ministerio Público" (Reformado mediante Decreto publicado en el Diario Oficial de la federación el 29 de enero de 2016). Por su parte, el art. 20 señala dentro de los derechos de la persona imputada que "Tendrá derecho a una defensa adecuada por abogado, al cual elegirá libremente incluso desde el momento de su detención. Si no quiere o no puede nombrar un abogado, después de haber sido requerido para hacerlo, el juez le designará un defensor público. También tendrá derecho a que su defensor comparezca en todos los actos del proceso y éste tendrá obligación de hacerlo cuantas veces se le requiera".

2 El art. 18 señala: "La operación del sistema en cada orden de gobierno estará a cargo de instituciones, tribunales y autoridades especializados en la procuración e impartición de justicia para adolescentes".

3 Esta ley también se conoce como la Ley DOF del 16 de junio de 2016 fue publicada en el Diario Oficial de la Federación.

4 La LNSIJA en su art. 67 señala: "La defensa, además de las obligaciones y atribuciones previstas por la Constitución, los Tratados Internacionales de los que el Estado mexicano sea parte, el Código Nacional y las leyes aplicables, tendrán las siguientes: i) realizar entrevistas para mantener comunicación constante con la persona adolescente y con sus responsables para informarles del estado del procedimiento; ii) informar de inmediato a las autoridades correspondientes cuando no se respeten los derechos de la persona adolescente o sea inminente su violación; iii) informar de inmediato a la persona adolescente su situación jurídica, así como los derechos y garantías que le otorgan las disposiciones legales aplicables, y iv) realizar todos los trámites o gestiones necesarios que garanticen a la persona adolescente una defensa técnica y adecuada". 
nuestro país en la actualidad, sin lugar a dudas destaca el realizado por Fix-Fierro y Abad denominado como "Diagnóstico del desempeño de las defensorías públicas en las entidades federativas" (Fix-Fierro \& Abad, 2015, 2016).

Como parte de las principales conclusiones de dicho estudio se señala: a) la existencia de importantes diferencias en la legislación en materia de defensorías públicas; b) que en su mayoría estas instituciones en los Estados conservan la estructura que tenían antes de la reforma, y c) que las leyes sobre el tema continúan centrándose en la regulación de la figura del defensor (Fix-Fierro \& Abad, 2015). Así mismo, a partir de datos empíricos recabados en diez entidades del país, los autores señalan que el proceso de implementación ha sido deficiente puesto que no muestra una dirección concreta y que existe un gran atraso en los temas de autonomía institucional, así como en el control de gestión. En contraste, donde se encontraron mayores avances fue en cuanto a la construcción de un servicio profesional de carrera, aunque las fallas en la generación de estímulos, la ausencia de capacitación en áreas relevantes y la falta de nivelación entre el salario de estos actores judiciales y el de los del ministerio público continúan sin resolverse en la mayor parte de las entidades del país (Fix-Fierro \& Abad, 2016).

Si bien el estudio realizado por Fix- Fierro \& Suárez (2016) concluye que la situación actual de las Defensorías Públicas debe comprenderse a partir de la falta de voluntad política para lograr que dicha institución opere de manera autónoma, así como que tenga un mejor control de sus procesos y presupuestos, mi interés específico fue estudiar el papel que la defensoría pública desempeña específicamente dentro del Sistema Integral de Justicia para Adolescentes a partir de un enfoque antropológico, que contribuya a comprender cuál es la relación que dicha institución guarda con la cultura jurídica en la cual México se inscribe.

Para tal efecto, el texto quedó dividido en dos secciones, en la primera de ellas describo brevemente la relación que históricamente el Estado estableció con este sector de la población a través del modelo tutelar, y las figuras encargadas de representarlos legalmente durante esos procedimientos. En la segunda sección planteo la impronta del ethos inquisitorial de larga data inscrita en dicha relación, y señalo algunos escenarios donde es posible ubicarlo actualmente a partir de los datos obtenidos en trabajo 
de campo. De manera específica, el argumento central consiste en que para operar de manera efectiva la defensa pública dentro del sistema penal acusatorio no solo se requiere que gocen de autonomía institucional, sino que, como institución oficial reconozca y modifique dicha impronta que el Estado mexicano ha establecido históricamente en la relación con las personas menores de edad acusadas de infringir la ley, y de la cual, como institución estatal, continúa abrevando.

\section{Los antecedentes de la defensa especializada en adolescentes en México}

De acuerdo con Azaola $(1990 ; 1996)$ en cuanto a la relación entre el Estado mexicano y la adolescencia transgresora de la ley es posible identificar tres etapas antes de la reforma de 2005: la fundación de los tribunales para menores entre los años 1920 y 1940, ${ }^{5}$ la sustitución de éstos por los Consejos Tutelares en la década de los setenta, ${ }^{6} \mathrm{y}$ finalmente, el surgimiento de los Consejos de Menores a inicios de los años noventa. ${ }^{7}$

5 Azaola señala la expedición del Reglamento para la Calificación de los Infractores Menores de Edad en el Distrito Federal en 1929, con el cual se creó el Tribunal Administrativo para Menores que estuvo integrado por tres jueces: un doctor y dos maestros. La autora llama la atención sobre el hecho de que en este periodo se consideraba que las conductas de los niños procesados se debían al conjunto de factores físicos, mentales, funcionales y morales hereditario. Así mismo, Azaola destaca que en este periodo el hecho por el que los niños eran procesados no era importante, sino el descubrimiento de lo que había "detrás", razones que se usaban para etiquetar a estos sujetos como "anormales" "patológicos" y "peligrosos". De ahí entonces que lo que más le importara al juez era determinar la "personalidad" del menor (1990, pp. 47-136).

6 Azaola plantea que la nueva legislación permitía que los Consejos Tutelares pudieran intervenir no sólo cuando los menores de edad trasgredieran la ley, sino también cuando se encontraran indicios de que tuvieran una inclinación a causar daños a sí mismos o a su familia, lo que amplió el poder del Estado para intervenir en la vida de los niños y adolescentes y mantiene el "carácter secreto" de sus procedimientos. Uno de los aspectos importantes es que en esta nueva etapa se establecieron plazos para los precedimientos aunque no se establecieron regulaciones respecto a las pruebas que podían admitirse, lo que implicó que todo quedaba a consideración de los Consejeros. En esta etapa además la autora señala que lo que se privilegió en el discurso oficial fue señalar la función protectora y rehabilitadora del Estado (Azaola, 1990, pp. 137-217).

7 En 1991 fue expedida la Ley para el tratamiento de menores infractores del Distrito Federal, que entre otras diferencias, establecía que el Estado no podría aplicar ningún procedimiento en los menores de edad si no había sido cometida alguna conducta establecida formalmente en los código penales; así como el derecho a un defensor de oficio (Azaola, 1996). 
A través del estudio de dichas etapas es posible plantear que, históricamente, el trato que el Estado mexicano ha dado a los niños y adolescentes antes del 2008 estuvo caracterizado por oscilar entre un modelo penal y uno asistencial, el cual, al tiempo promovía una imagen de Estado protector ocultaba el castigo hacia los niños y adolescentes bajo argumentos "científicos" y "técnicos", por medio de los cuales ejercía en ellos un poder completamente arbitrario y discrecional. A partir de esto, el Estado estableció una manera específica de mirar a los adolescentes que priorizaba el encierro de aquellos considerados en "riesgo" de cometer una conducta antisocial o ser víctimas de algún delito (Azaola, 1990).

Al concebir a los niños y adolescentes como seres "incapaces" o "inviables", las autoridades se adjudicaban libremente el poder de detener e internar a los niños y adolescentes a través de la solicitud de sus familiares, a criterio de policías o cualquier otra autoridad inmiscuida. Además de lo anterior, resulta necesario resaltar otros dos elementos: el primero es que en la práctica los menores que eran objeto de este tipo de tratamiento se distinguían principalmente por vivir en condiciones de pobreza, ${ }^{8}$ así como que el proceso que se seguía para internar a los menores era de índole administrativo, toda vez que la institución pertenecía al poder ejecutivo. La suma de dichas cuestiones, primero, ser considerados como "menores" e "incapaces"; segundo, ser pobres, y finalmente, recibir un procesamiento administrativo y no judicial, determinaba que estos niños y adolescentes quedaran completamente a merced del poder estatal.

En este punto, Azaola refiere que en 1974, cuando se dictó la ley que creó los Consejos Tutelares para los Menores Infractores, se planteó la figura del "promotor", quien fungía como "una especie de abogado del menor" y se les adscribió como miembro del Consejo (el órgano regulador de la institución), sin que realmente se les reconociera un estatus similar o autonomía. Como la autora destaca, si bien en dicha ley se facultaba a los promotores a impugnar las resoluciones del Consejo, lo cierto es que en la práctica esto no sucedía debido a la existencia de un acuerdo tácito para no cuestionar a los otros integrantes. En este sentido,

8 Es interesante ubicar que el mismo paradigma tutelar operó de manera muy similar en Argentina y Brasil (Villalta, 2004, 2005, 2013; Schuch, 2012, 2009) obteniendo básicamente los mismos resultados respecto a la institucionalización de la exclusión de la niñez y adolescencia pobre. 
el promotor únicamente podía participar proponiendo que se aplicaran pruebas y asistir a su desahogo y visitar a los menores en los Consejos Tutelares para vigilar la ejecución de las medidas impuestas. Sin embargo, lo que sí podían hacer en la práctica era impugnar la resolución y solicitar medidas más severas de las que éste había propuesto a los menores, con lo cual queda claro que su papel estaba lejos de constituir una efectiva defensa (Azaola, 1990).

$\mathrm{Al}$ respecto resulta importante señalar algunos aspectos: primero, dentro del modelo tutelar se establecía que: "[...] a diferencia de los jueces penales para adultos, la acción de los consejeros solo se ve limitada por la obligación de escuchar al menor, admitir la presencia del promotor en todo el procedimiento y expresar en sus resoluciones los «fundamentos legales y técnicos que las sustentan»" (Azaola, 1990, p. 156). Sin embargo, como la autora plantea, podemos suponer que, en un escenario con desequilibrios de poder tan evidentes entre los mismos operadores del sistema y marcado por la criminalización de la pobreza, las voces de los niños y adolescentes no eran escuchadas. En este sentido, lo más importante para Azaola no solo es notar que la posibilidad de que estos sujetos contaran con una verdadera defensa sensible a sus condiciones sociales y familiares se esfumó por completo al no dotarla de autonomía, sino que realmente nunca habría podido existir debido a la posición positivista, formalista y adultocéntrica con que todo este modelo operó, el cual reducía a los niños y adolescentes a simples espectadores y receptáculos de sus designios.

Como resultado de un esquema en donde el Estado se había colocado a sí mismo y asumía en un solo órgano dependiente del Ejecutivo tanto las funciones de procurador, como las de defensor y juzgador, pero también las de protector y las de encargado del imponer, ejecutar y supervisar las sanciones, se había llegado al punto en que los menores habían perdido todos los derechos de cualquier persona sujeta a un procedimiento penal. (Azaola, 1996, pp. 23-24)

A partir de la presión internacional, solo hasta 1991 se introdujo en México el paradigma "garantista" en el tratamiento hacia estos jóvenes de acuerdo con Azaola, es decir, se dieron una serie de cambios 
legislativos que incluían la figura del "defensor". Sin embargo, como institución estos quedaron dependientes del poder ejecutivo, lo que en la práctica continúo neutralizando su papel y, en términos sustanciales, esto cambió poco la situación que enfrentaban los niños y adolescentes al interior del Consejo Tutelar.

En este escenario, es importante es destacar que antes de las reformas en cuestión ambos modelos, tanto en el que procesaban (administrativamente) a los adolescentes, como en el que procesaban (judicialmente) a los adultos, tenían en común las arbitrariedades propias del desequilibrio de poder entre el órgano acusador, la autoridad que toma la determinación (sea juez en el sistema de adultos o presidente del Consejo en el modelo tutelar) y los defensores. Más aún, comparten una recalcitrante invisibilización y exclusión discursiva de los sujetos a quienes procesaban.

Por otra parte, es importante considerar que el modelo penal mixto para juzgar a los adultos que operó hasta antes del 2008 compartía aspectos esenciales del modelo para adolescentes pues estuvo caracterizado por: a) la concentración de funciones en una misma autoridad (el juez), quien ostentaba la facultad de investigar, acusar y juzgar; b) estar centrado en el expediente y que todo lo que no estuviera ahí escrito quedara fuera de juicio; c) la recurrente ausencia de la presencia del juez en el desahogo de pruebas y el dictado de sentencias sin que las partes hubieran conocido o hablado directamente con éste; d) limitación de la participación y posibilidades de la defensa; e) práctica generalizada del uso de la prisión preventiva; f) persecución del imputado y uso de la tortura; g) la confesión del imputado era considerada la "reina de las pruebas" (Carbonell E Ochoa, 2010; Díaz-Aranda, Roxin E Ochoa, 2014).

En otras palabras, en caso del sistema mixto aplicado a personas adultas acusadas de transgredir la ley penal, los sujetos sobre quienes se imponía un proceso penal se convertían en simples números de expedientes puesto que éstos muchas veces ni siquiera llegaba conocer al juez que tomaba determinaciones sobre sus vidas y sus posesiones. Además, existen estudios que muestran los altos índices de personas no sentenciadas recluidas en las cárceles hacinadas, los métodos de tortura usados por los policías al momento de interrogarlos, así como los casos de corrupción y extorsión cometidos por los operadores del sistema que obligaban a los ciudadanos a pagar por agilizar sus juicios. 
Ahora bien, de acuerdo con Vasconcelos (2012) el Estado mexicano "inventó" un sistema penal juvenil por primera vez en nuestra historia a partir de las reformas a los artículos 18,20 y $1^{\circ}$ de la Constitución Federal. ${ }^{9}$ Estas reformas, en conjunto, extrajeron a los adolescentes del poder ejecutivo donde eran tratados como infractores y los regresó al poder judicial, para ser tratados como personas en conflicto con la ley penal. A partir de esto dejaron de ser procesados administrativamente bajo el enfoque tutelar que los concebía como menores, para ahora ser procesados judicialmente bajo el enfoque de la responsabilidad penal progresiva. Con ello, jurídicamente dejaron de ser vistos como objeto de tutela para ser concebidos ahora como sujetos de derecho (Azzolini, 2009; Vasconcelos, 2012)..$^{10}$

En este escenario, la defensa especializada de adolescentes emergió como el tercer protagonista del trinomio judicial conformado junto con los jueces y los fiscales especializados en los jóvenes, ${ }^{11}$ y se enfatizó que los adolescentes podrían incluso participar activamente en su defensa. Los juristas entonces proclamaron que estábamos ante una nueva época en la relación entre el Estado y la adolescencia en conflicto con la ley penal (Azzolini, 2009; Vasconcelos, 2012). Sin embargo, fue hasta 2016 que se generó la Ley Nacional del Sistema Integral de Justicia Penal para Adolescentes (en adelante LNSIJPA), la cual derogó todas las legislaciones estatales y unificó criterios en el tratamiento a estos jóvenes.

9 La reforma de 2005 insertó en nuestra Constitución los aspectos más importantes de la Convención de Derechos del Niño, así como el sistema de justicia para adolescentes; la del 2008 impuso el sistema acusatorio para juzgarlos y la del 2011 introdujo el concepto de Derehos Humanos.

10 En este punto es importante señalar que, si bien la Constitución Federal ha ordenado instaurar el modelo acusatorio para juzgar a los adolescentes actualmente, existen estados donde los han integrado al sistema mixto, las razones para ello podrían situarse en la falta de presupuesto para implementar este nuevo modelo (Censo Nacional de Impartición de Justicia Estatal 2016 del INEGI, 2017). Véase http://www.beta.inegi.org.mx/app/biblioteca/ficha.html?upc=702825091583

11 Si bien conozco los interesantes debates en torno a los límites etarios y su implicación social y jurídica, en el presente texto usaré indistintamente los términos jóvenes para hacer referencia a las personas mayores de catorce años y menores de dieciocho años que son acusados de cometer una conducta sancionable por la ley penal. 


\section{La impronta del ethos inquisitorial y sus implicaciones prácticas en la defensa especializada en adolescentes}

Hace casi tres décadas el planteamiento de la categoría "sensibilidades jurídicas" realizado por Geertz (1994), para designar la forma como el grupo da sentido a lo que hace (en términos prácticos, morales, expresivos y jurídicos), mientras ajusta esto en marcos más amplios de significación en relación al derecho, marcó un hito en nuestra subdisciplina. De acuerdo con Kant, el hecho de que Geertz destacara la necesidad de comprender la manera como tales sensibilidades se diferencian entre sí a partir del grado de determinación, el poder que ejercen (en relación a otros modos de pensamiento y sobre los procesos de la vida social), así como en sus estilos y contenidos particulares del derecho, ha permitido poder enfocarnos ahora en comprender la existencia de diversas sensibilidades jurídicas (sentidos de justicia o regímenes de verdad como a éstas también se refiere Kant) en occidente (Kant, 2009).

En este sentido, retomando el planteamiento de Foucault respecto al vínculo político que el proceso judicial establece entre el Estado y el individuo, Garapon y Papadopulos (2008) proponen que cada cultura jurídica opera y se retroalimenta a partir de una relación política y simbólica distinta entre ambos a través del derecho. Los autores destacaron entonces la necesidad de entender, en primer lugar, la manera en que esa relación posibilita la construcción de prácticas en torno al derecho, como herramienta del ejercicio del poder, y de la legitimidad estatal; así mismo, plantearon la importancia de analizar las reglas jurídicas en conjunto con la observación de las prácticas penales, de manera que se logre establecer la concepción del individuo con que operan, como una vía para entender los vínculos que la justicia establece con la política, en lo que se pudiera pensar como una "dimensión profunda" acerca de la relación Estado-individuo a través del derecho.

A partir de los planteamientos de Garapon y Papadopulos (2008), en nuestros días podemos ubicar la predominancia de dos grandes configuraciones jurídicas: el civil law y el common law, mismas que en mayor o menor medida, a partir del proceso histórico de la Colonización impregnaron una considerable parte de Occidente, y generaron sensibilidades propias en torno al derecho. Dentro de esta línea de trabajo, la propuesta 
de Kant de Lima (2008) toma gran relevancia para comprender las particularidades que la cultura jurídica de origen en la familia del civil law imprimen en nuestros sistemas jurídicos actuales

A partir de la lectura de Kant (2009), es posible usar el término ethos inquisitorial para designar los elementos característicos del proceso inquisitorio, como son una pulsión por concebir el derecho como esencia coherente, neutral y superior; una percepción de los sujetos procesados como necesariamente hiposuficientes; la sospecha de la culpabilidad de éstos como una condición que justifica su existencia como autoridades; así como el secreto y/o prácticas oscuras de procesamiento y como modus operandi, principalmente. Así mismo, como al conjunto de relaciones asimétricas establecidas de los operadores hacia los sujetos procesados (así como entre los mismos operadores) que pueden ser comprendidas como producto y reproductores de dicho ethos.

Ahora bien, señalo la necesidad de ubicar el ethos inquisitorial latente en el surgimiento de la defensa especializada en adolescentes, en la medida enque éste condensa los aspectos más profundos de los dos modelos de relación que el Estado mexicano estableció para tratar a los menores que cometían infracciones (el proceso administrativo del modelo tutelar), así como a los adultos que cometían delitos (proceso judicial del modelo mixto). Para tal fin retomé datos etnográficos recopilados durante el periodo de trabajo de campo realizado en el marco de la estancia posdoctoral realizada en el Instituto de Investigaciones Jurídicas de la Universidad Nacional Autónoma de México (IIJ-UNAM) bajo la asesoría del Dr. Héctor Fix Fierro entre el 2016 y el 2017. En dicho periodo realicé una serie de entrevistas a operadores del sistema penal para adolescentes en el estado de Morelos; también realicé etnografías y revisión de videograbaciones judiciales de distintas audiencias públicas de procesos penales donde los/ las acusadas fueron adolescentes. ${ }^{12}$

12 Las entrevistas realizadas a operadores del sistema penal para adolescentes fueron las siguientes: presidenta del Tribunal Unitario de Justicia para Adolescentes (1); jueces (3); juez de ejecución de medidas (1); coordinadores de la Unidad de medidas cautelares (1). Respecto a las entrevistas realizadas a los defensores públicos cabe destacar que se logró entrevistar a dos de los tres defensores especializados en materia de adolescentes. Así mismo, se realizaron etnografías de juicio oral (10) y revisión de videograbaciones judiciales de diferentes tipos de audiencias (12). El periodo de trabajo estuvo comprendido entre abril-junio de 2017 en distintas instituciones que conforman el sistema penal juvenil del estado de Morelos, México, radicadas en la ciudad de Cuernavaca. 
En este tenor de ideas, Garapón y Papadopulos plantean tres ejes esenciales propuestos para analizar la cultura jurídica del civil law, entre otros: a) la relación entre el derecho y el individuo, b) los vínculos entre el proceso judicial y el acceso a la justicia, y c) la relación entre la verdad y la prueba, como coordenadas que permitirán mostrar que, para cumplir la función que el garantismo y el modelo acusatorio le imponen, más allá de una mayor autonomía la defensa especializada en adolescentes requiere desarrollar mecanismos que le permitan disminuir la impronta del ethos inquisitorial que el Estado mexicano ha establecido en la relación con las personas menores de edad acusadas de infringir la ley.

En el primer eje, enfocado a la relación entre el derecho y el individuo, lo primero que es preciso destacar es que, de acuerdo con Garapón y Papadopulos, en el caso del civil law esta es dada a partir de una concepción del derecho en tanto esencia, fruto de un pensamiento lógico, racional y universal. Desde este enfoque, el derecho es establecido como principio del orden social, como un ideal al cual dirigirse, lo que requiere que la sociedad deba ser organizada desde una voluntad política "superior", que le dé forma. Como los autores señalan, tal situación impone que el derecho deba provenir del Estado, razón por la cual los especialistas jurídicos se vuelven necesarios, como una suerte de "traductores" e intermediarios entre el Estado y el individuo. Esto determinará que esa relación sea lejana y en todo momento debe estar intervenida por especialistas encargados de traducir y vigilar el respeto a la sacralidad del derecho.

A partir de lo anterior, considero que podemos ubicar el ethos inquisitorial existente en la justicia para adolescentes en la medida de que persiste y enfatiza la necesidad de contar con intermediarios entre el Estado y los adolescentes que funjan como traductores del (nuevo) derecho especialmente designado a éstos; entre los cuales el defensor se distingue, se le exige formalmente dicha especialización. Señalo esto como una continuidad, en la medida de que históricamente si algo caracterizó al Modelo Tutelar fue la pugna por instaurar un campo distinguido también por el lugar que ocupaba la especialización de sus actores respecto a las cuestiones correccionales que conllevaran a su rehabilitación (Azaola, 1990). En este punto cabe destacar que, si bien dicho ethos no es exclusivo del sistema penal para adolescentes, sino que por el contrario, está presente 
en todo el sistema penal mexicano, en mi opinión las repercusiones que tiene en el acceso a la justicia penal juvenil adquieren características que deben ser estudiadas de manera más enfática.

Lo interesante en todo caso es ver que ahora la LNSIJPA establece la especialización, la cual se da cuando se acreditan los siguientes conocimientos y habilidades: 1) conocimientos interdisciplinarios en materia de derechos de niñas, niños y adolescentes; 2 ) conocimientos específicos sobre el Sistema Integral de Justicia Penal para Adolescentes; 3) conocimientos del sistema penal acusatorio, las medidas de sanción especiales y la prevención del delito para adolescentes, y 4) el desarrollo de habilidades para el trabajo con adolescentes en el ámbito de sus respectivas competencias (Art. 64).

Si lo analizamos con más cuidado podemos apreciar que en ambos esquemas, el tutelar y el acusatorio, el mayor énfasis se hace en cuanto al sistema procesal, así como en las medidas de sanción. Además de esto, cabe destacar que durante el trabajo de campo algo que resaltó fue que, en la práctica, la institución no les brinda dicha especialización formalmente, sino que se da "sobre terreno", es decir, cuando se designa que un nuevo defensor para este sector de la población se le ordena acompañar a sus compañeros con más antigüedad para que aprenda "el oficio", como en el caso de Morelos.

En este punto, es interesante señalar que cuando pregunté a los defensores a qué se refería la defensa adecuada en la práctica, sus respuestas siempre ubicaban el mayor énfasis en los aspectos formales del sistema penal:

Pues en que realice todos los actos idóneos para poder sacar adelante el asunto [...]. Por ejemplo, en primer lugar, es que conozca el sistema [...]. Cada audiencia tiene un tope, tiene un por qué, tiene una finalidad. Entonces si llego y me pierdo ya en la etapa y estas manifestaciones que hago no son la idóneas, pues obviamente desde ahí estoy llevando mal la defensa, el proceso. Entonces la defensa técnica adecuada es pues más de conocimiento del sistema [...] falta mucha capacitación. [...] entonces esa es exactamente la defensa técnica adecuada, conocer bien cuáles son las etapas del procedimiento, que cada etapa tiene su tope, hacer las manifestaciones pertinentes a las que van encaminadas a cada una de las etapas, conocer cómo se hace una investigación y me refiero 
a conocer así todo el sistema; pues de ello depende, o sea, si yo no sé cuáles son las funciones del policía, pues cuando yo lo interrogue no voy a saber en qué está fallando los peritos y esa es la defensa técnica adecuada. (Defensor, entrevista realizada el 16 de febrero de 2017)

Como podemos observar, los mismos defensores especializados en adolescentes muestran una especial atención a los aspectos técnicos formales, invisibilizando aquellos que certifiquen un mayor conocimiento social sobre los sujetos a quienes representan y que tendría que estar enfocada en ubicar, resaltar y defender la particularidad del sujeto que defiende, es decir, las condiciones psicológicas, físicas y socioculturales que llevan a que la responsabilidad penal sea progresiva. Por ejemplo, el papel que desempeña el desarrollo del lóbulo frontal en la toma de decisiones y la emoción por el peligro (Oliva, 2007), el tipo de vínculos de socialización que pueden generar al interior de bandas juveniles (Valenzuela, 2009), la complejidad involucrada en las relaciones y estereotipos de género en sus interacciones sociales (Meo, 1995), así como la importancia que tiene comprender que la adolescencia y la juventud son constructos sociales atravesados por el género, la adscripción étnica y la clase (Bourdieu, 1990; López, 2017; Islas, Valdez \& Suárez, 2008; Reguillo, 2010; Urteaga, 2011; García Álvarez, 2006), por mencionar solamente algunos.

Por otra parte, se debe destacar que el modelo tutelar estuvo sustentando en la noción del "menor en riesgo", del cual se pensaba que cometía "infracciones" al ser incapaz de responsabilizarse penalmente de sus actos (inimputable), y que ahora el nuevo sistema se finca sobre la noción de los adolescentes como sujetos de derecho, es decir, como seres capaces de accionar el derecho, responsabilizarse de sus deberes y acciones. A raíz de lo anterior, se cambió también la concepción de "interés superior del menor" por el de "interés superior del adolescente".

Indudablemente, esto en términos dogmáticos constituye un enorme avance. Sin embargo, como el trabajo de campo permitió comprender, en la medida en que quienes siguen definiendo qué es el interés superior del sujeto en cuestión son exclusivamente los representantes del Estado (los intermediarios y traductores) y que esto lo determinan desde una posición completamente adultocéntrica y formalista, este cambio consistió 
en algo más nominal que sustancial. Más aun, como fuera señalado en la tesis doctoral (Juárez, 2016) y reafirmado ahora durante la presente investigación, si algo caracteriza los procesos judiciales para adolescentes es el silencio generalizado en el que el sistema los sumerge; aun cuando formalmente existen momentos específicos para que el juez pregunte a los adolescentes si quieren declarar o realizar alguna manifestación, lo común es observar que estos no intervienen en sus juicios. ${ }^{13}$

Entonces, es preciso enfatizar que los adolescentes continúan siendo invisibilizados y excluidos discursiva y simbólicamente de forma sistemática de sus propios procesos judiciales, toda vez que, como ya fuera señalado, en el modelo Tutelar se estableció que el papel de los consejeros era escuchar a los menores y ahora, en la LNSIJPA se estipula que los adolescentes tienen derecho a ser escuchados y tomados en cuenta directamente "en cualquier etapa del procedimiento, tomando en consideración su edad, estado de desarrollo evolutivo, cognoscitivo y madurez" (Art.43), estas buenas intenciones siguen siendo opacadas o neutralizadas en el nuevo sistema.

También es importante resaltar que el adultocentrismo y formalismo que caracteriza a los operadores del sistema penal juvenil también se encuentra presente en los defensores especializados. Durante el trabajo de campo me percaté de que estos actores generalmente destinan apenas unos pocos minutos para interactuar con los adolescentes que represen$\tan ^{14}$ y que cuando lo hacen esto se parece más a un microinterrogatorio. Durante las charlas informales que tuve con los defensores en los pasillos de las salas de audiencia, cuando les hacía notar la brevedad de tales interacciones, fue común recibir como respuesta que esto se debía a que

13 A partir de una serie de elementos etnográficos (entrevistas a adolescentes, sus familias, jueces, magistrados, sus víctimas; la revisión de carpetas y videos judiciales, visitas al centro de internamiento y sus hogares, la etnografía de audiencias) propuse entonces en la investigación doctoral que la reforma únicamente había logrado trasformar la dimensión "formal" de la relación entre el Estado y estos jóvenes, y no así su dimensión "simbólica", en la medida que a pesar de las reformas no había sido capaz de eliminar la "exclusión discursiva" y las prácticas arbitrarias de sus operadores hacia los adolescentes y que eran percibidos como un "insulto moral"; esto es, siguiendo a Cardoso (2011, 2010, 2004), como agravios a su dignidad.

14 Es interesante notar que, al igual que sucede en la investigación de Eilbaum (2012) realizada en el contexto argentino, los defensores no suelen hablar a profundidad con los jóvenes puesto que esto puede ser considerado "um luxo que os defensores públicos nao podem se dar" (Eilbaum, 2012, p. 183). 
tenían sobrecarga de trabajo y que, con base a su experiencia, detectaban fácilmente las mentiras de los jóvenes. Es decir, según ellos, se daba una extraña trasmutación de "su experiencia" con los adolescentes hacia el desarrollo de una habilidad extrasensorial de "detección de mentiras", basada principalmente en el análisis del lenguaje corporal del adolescente en cuestión, misma que es compartida posteriormente con el resto de los operadores judiciales, que llegan a tener expresiones extremas del tipo: "yo en cuanto veo a los adolescentes entrar ya sé si son culpables o no". Lo que resulta más grave en todo esto es que al momento de emitir dichas evaluaciones ninguno de estos actores toma consciencia ni se responsabiliza de los estereotipos de clase y género a partir de los cuales desempeña sus funciones, así como tampoco considera la importancia de las transiciones vulnerables ${ }^{15}$ de donde provienen estos adolescentes (Saraví, 2009, 2006); ni de su paso al interior de la maquinaria penal del Estado donde la violencia física, psicológica y simbólica es recurrente (Azaola 1990, 2006; Juárez, 2016). ${ }^{16}$

Por otro lado, en cuanto a la relación entre el proceso judicial y el acceso a la justicia Garapón y Papadopulos señalan la importancia de identificar la fuerza que pone al proceso en acción. En la tradición jurídica del civil law el proceso judicial inicia con el acto de acusación activado por el Estado, en tanto poder público, y lo que se busca con sus ceremonias es reconstruir la soberanía del Estado donde el sujeto debe purgar la insolencia por trasgredir el orden tutelado. En este contexto destaca que la investigación inicial está fundada sobre la sospecha de la culpabilidad

15 Concepto sociológico sobre la juventud en contextos de exclusión social propuesto por Saraví que hace alusión a un enfoque sociológico sobre la juventud en contextos de exclusión social que centra sus esfuerzos en la comprensión de la manera como la presencia de diversos factores de riesgo puede generar y reforzar restricciones sobre posibilidades futuras. El concepto refiere por tanto a los procesos de acumulación de desventajas que los jóvenes enfrentan y que pueden llevarlos a quedar atrapados en situaciones de desventajas crónicas.

16 En este punto es importante señalar que el informe especial Adolescentes: vulnerabilidad y violencia realizado por la Comisión Nacional de Derechos Humanos y el Centro de Investigaciones y Estudios Superiores en Antropología Social (CNDH-CIESAS, 2017) a partir de las encuestas realizadas y complementadas con entrevistas en diversas entidades del país, plantea, entre otras cuestiones, que el $57 \%$ de los adolescentes señaló ser severamente golpeados y maltratados por diferentes corporaciones policiales (incluso el citado estudio describe algunas de las torturas descritas por los entrevistados); el $59 \%$ no le informaron el delito por el que lo detenían; el 53 \% no fue presentado de inmediato ante Ministerio Público; y al 54 \% no le informaron el derecho a un abogado. 
de los acusados y, por tanto, sobre un embrión de juzgamiento. La detención provisional entonces puede ser analizada como una apuesta en la culpabilidad, que el proceso confirmará. De ahí entonces que, de acuerdo a los autores, no se ponen en igualdad de circunstancias las diferentes versiones de los hechos, sino que limita los debates dentro de un sistema de referencia que ponen al centro - con mayor poder-, el acto de la acusación, cuya lectura inicia el trabajo del tribunal. Más aún, todo esto se maneja de tal forma que se deja poco espacio para las dudas, ante lo cual, el defensor rara vez puede oponer una versión verosímil de los hechos, puesto que no dispone de los recursos humanos y materiales necesarios para cumplir adecuadamente sus funciones. Por tanto, la única acción verdadera de los defensores termina reduciéndose a intentar atacar la sentencia del juez por medio de demandas de anulación de la sentencia, en instancias superiores.

Al respecto, el trabajo de campo realizado en los estados de Morelos y Querétaro mostró que en el nuevo sistema de justicia penal juvenil continúa existiendo un marcado desequilibrio de fuerzas entre el órgano acusador y la defensa, es decir, la defensa no cuenta con los recursos (financieros, técnicos) para realizar verdaderas tareas de investigación de los "hechos" en campo, lo que repercute en un mínimo poder de generación de "indicios de pruebas" que podrían permitirle construir versiones de los hechos realmente diferentes a la que el fiscal presenta, lo que casi de manera automática se traduce en que la mayoría de las veces sea la defensa pasiva la única que pueden oponer como práctica recurrente. Además, llama la atención que en este punto los jueces y fiscales coincidan en que tal situación no violenta el derecho de defensa de los adolescentes, ya que por ley la fiscalía lleva "la carga de la prueba" (está obligado a aportar las pruebas para demostrar la culpabilidad del acusado).

Me parece entonces que este es uno de los elementos donde más podemos apreciar la persistencia del ethos inquisitorial, es decir, el modelo acusatorio impone la igualdad de condiciones para ambas partes (el fiscal y el defensor) como requisito indispensable para lograr el acceso a la justicia por medio del proceso judicial y esto está actualmente considerado en la normatividad correspondiente; sin embargo, tal como sucede en otros aspectos, en la realidad esto opera de manera muy distinta. 
El tema es grave si consideramos una cuestión tan básica como el hecho de que si el defensor no cuenta con los medios necesarios para acudir al lugar de los hechos, tomar fotografías o videograbaciones, o incluso contactar posibles testigos, sin duda puede estar perdiendo importantes insumos para la elaboración de su teoría del caso. Un ejemplo es que los defensores generalmente toman fotografías con sus celulares personales y piden que sean los familiares del adolescente quienes localicen a los testigos a su favor, ya que no cuentan con equipos, puesto que las instituciones no los dotan de los recursos necesarios para hacerlo.

Del mismo modo, en la observación de audiencias, la revisión de videograbaciones judiciales y expedientes, otra de las cuestiones que surgió fue el mínimo uso de técnicas y destrezas de litigación. Por tales me refiero a las herramientas que el sistema penal acusatorio plantea para el desarrollo de la participación y acciones concretas que los defensores tienen frente al resto de los actores jurídicos (jueces, magistrados, fiscales, policías, peritos de la fiscalía y testigos), para defender al adolescente en la sala de audiencia al momento del juicio oral, entre estas: 1) un uso estratégico de los alegatos de apertura y cierre; 2 ) las objeciones; 3 ) el uso de prueba material, documental y otros tipos de pruebas.

Otro aspecto donde podemos apreciar la persistencia del ethos insiuqitorial es en el desequilibrio de poder y de recursos que la defensa enfrenta ante las declaraciones de la policía, y que generalmente constituyen el centro de las teorías del caso de los fiscales. Me refiero a que es común que los fiscales usen la detención en flagrancia como argumento para solicitar que los adolescentes queden vinculados a proceso judicial y que los defensores señalen inconsistencias al respecto.

Ejemplo de esto se encuentra cuando un policía dice que el adolescente iba acompañado o llevaba algún objeto, que opuso resistencia a la detención o que incluso no lo detuvieron en la calle mientras la defensa sostiene que lo sacaron a la fuerza o con engaños de su casa. Sin embargo, la defensa poco puede hacer al respecto, pues ante las preguntas o la sospecha de contradicción los policías suelen responder: "hace mucho tiempo que presenté ese informe, no recuerdo los detalles, todo quedó registrado", "mensualmente participo de muchas detenciones y no puedo recordar todos los detalles después de tanto tiempo, para eso elaboramos los informes". 
Es decir, si bien el sistema acusatorio instaurado para adolescentes exige que todas las pruebas y testimonios sean incorporados de forma oral y que esto implica que los policías y testigos deban presentarse físicamente en la sala de audiencias y decir frente al juez, el defensor y el adolescente por qué detuvieron al joven como garantía de contradicción, en la práctica esto poco ha cambiado las arbitrariedades que estos comenten contra los jóvenes y el tipo de respuesta que la defensa puede oponer. En tales circunstancias, el resultado final es que se libra una lucha entre "el dicho" de la defensa y el del fiscal o policía y lo cuestionable es que continúen teniendo más peso estas últimas.

Finalmente, en lo que se refiere al análisis del vínculo entre la verdad y la prueba, Garapon y Papadopulos sostienen que en el civil law éste queda directamente relacionado con el catolicismo y marcado por la centralización en la autoridad de la iglesia, a partir de lo cual se puede comprender el fuerte apego a la autoridad doctrinal y a su jerarquización. Desde esta lógica se impone que la condición para establecer la verdad factual y para restablecer la verdad oficial, requiere la rendición del sujeto ante la institución, la cual toma la forma de la confesión. Para los autores comparar la confesión católica y la confesión en los procedimientos de investigación tiene lógica si se considera que en sí misma, la confesión impone una relación vertical y autoritaria entre un investigador y una persona puesta a prueba. Aunado a esto, los autores refieren que en la cultura del civil law existe una "racionalidad burocrática" de la prueba.

En este último eje es importante destacar que la LNSIJPA establece el derecho de los adolescentes de ser escuchados en todo lo que les compete (Art. 43). Sin embargo, la misma normatividad señala la abstención de declarar como otro de sus derechos (Art. 45). Así mismo, en este aspecto es importante señalar que la citada ley ordena la imposibilidad de que se condene a los adolescentes "con el sólo mérito de su propia declaración" (Art.143). Es decir, aun cuando los jóvenes acepten su participación en los hechos que se les imputan directamente o su responsabilidad pueda ser derivada de ésta, es preciso que existan otros elementos de prueba que lo demuestren. Sin embargo, lo cierto es que, aunque ahora negado oficialmente, la "confesión" continúa teniendo un gran peso en la medida en que, en la práctica, lo que más peso puede tener es la "declaración" que pueda hacer el adolescente, y que por eso 
la generalidad es que la defensa tenga como estrategia central el uso del silencio del adolescente, estrategia que continúa perpetuando la exclusión discursiva de los jóvenes en sus propios procesos penales.

\section{Palabras finales}

Considero que en el caso de la justicia para adolescentes en México todo lo anteriormente expuesto constituye un elemento que permite ver el ethos inquisitorial, en la medida en que el único uso que en realidad se le da a la "declaración" de los jóvenes es para usarla en su contra, para ubicar en ella cada resquicio de culpabilidad, criminalidad y anormalidad que permitan justificar que el Estado debe sancionarlo. Al respecto, Cardoso (2011) plantea la exclusión discursiva como la dificultad de las instituciones y actores del Estado de escuchar sustantivamente a los actores implicados en procesos judiciales, la cual tiene una íntima conexión con procesos de comunicación donde existen marcadas relaciones de poder.

En este sentido, es posible sostener que, si bien la autonomía técnica y presupuestal de la institución encargada de brindar la defensa técnica especializada en adolescentes es urgente y necesaria, el cambio efectivo se logrará únicamente en la medida que sean ubicados y se desarrollen mecanismos que le permitan disminuir la impronta del ethos inquisitorial que el Estado mexicano ha establecido en la relación con las personas menores de edad acusadas de trasgredir la ley penal.

\section{Referencias}

Azaola, E. (1996). Posibilidades y límites de dos modelos de justica para menores. Cuádrenos del Instituto (1), 19-32.

Azaola, E. (1990). La institución correccional en México. Una mirada extraviada. Ciudad de México: CIESAS-Siglo XXI.

Azaola, E. (2016). Adolescentes: vulnerabilidad y violencia. Ciudad de México: CIESAS-CNDH.

Azzolini, A. \& Rojas, A. (2009). 20 reglas básicas de la justicia para adolescentes. Ciudad de México: Unilus, Procuraduría General de Justicia del Distrito Federal. 
Bourdieu P. (1990). La juventud no es más que una palabra. En Sociología y cultura, 163-173. Ciudad de México: Grijalbo/CNCA.

Cámara de Diputados del H. Congreso de la Unión. (2016). Ley Nacional del Sistema Integral de Justicia Penal para Adolescentes. Diario Oficial de la Federación. Recuperado de http://www.diputados.gob.mx/LeyesBiblio/pdf/ LNSIJPA.pdf

Carbonel, M. E Ochoa, E. (2010). ¿Qué son y para qué sirven los juicios orales? México: Porrúa-Renace-UNAM.

Cardoso, L. (2011). Prefacio. En F. M. Meriti de Souza E J. Newton Garcia de Araújo (Coords.), Dimensões da violência: conhecimento, subjetividade e sofrimento psíquico (pp. 5-13). São Paulo, Brasil: Editora Casa do Psicólogo. Cardoso, L. (2010). A dimensão simbólica dos direitos e a análise de conflitos. Revista de Antropología de Social, (53), 451-473.

Cardoso, L. (2004). Honor, Dignidad y Reciprocidad. Cuadernos de Antropología Social, (20), 25-39.

García Álvarez, L. F. (2006). Juventudes y violencias contemporáneas en Latinoamérica. Revista nuestrAmérica 4(8), 5-10.

Díaz-Aranda, E., Roxin, C. E Ochoa, C. (2014). Lineamientos prácticos de teoría del delito y proceso penal acusatorio. Conforme a las reformas constitucionales de 2008-2011, los Tratados Internacionales y al Código Nacional de Procedimientos Penales, Ciudad de México: STRAF.

Fix-Fierro, H. \& Suárez, A. (2015). Hacia una defensa pública de calidad. El nuevo diseño institucional de las defensorías públicas en las entidades federativas de la república mexicana. Revista Mexicana de Derecho Constitucional, (32), 157-200.

Fix-Fierro, H. G Suárez, A. (2016). ¿El renacimiento de la Defensoría Pública en México. Análisis del proceso de implementación de las Instituciones de Defensoría Pública en las entidades federativas. Ciudad de México: Instituto de Investigaciones Jurídicas de la Universidad Nacional Autónoma de México.

Garapon, A. E Papadopoulos, L. (2008). Julgar nos Estados Unidos e na França. Río de Janeiro: Lúmen Júris Editora.

Geertz, C. (1994). Conocimiento local. Ensayos sobre interpretación de las culturas. Barcelona: Paidós.

INEGI (2017). Censo Nacional de Impartición de Justicia Estatal 2016 del INEGI. Ciudad de México: INEGI.

Juárez, I. (2016). Reformas, procesos y trayectorias. Análisis antropológico del proceso judicial para adolescentes dentro del modelo acusatorio, en el estado de Querétaro (Tesis doctoral), CIESAS. Ciudad de México, México. 
Kant, R. (2008). Por uma Antropologia do Direito, no Brasil. Ensaios de Antropologia e Direito, 43-57. Río de Janeiro: Lúmen Júris Editora.

Kant, R. (2009). Sensibilidades jurídicas, saber e poder: bases culturais de alguns aspectos do direito brasileiro em uma perspectiva comparada. Anuario antropológico, (2), 25-51.

López Guerrero, J. (2017). Mujeres jóvenes indígenas migrantes en la zona metropolitana del valle de México. Condiciones estructurales y subjetividades en la construcción de su experiência juvenil. Ciudad de México: Universidad Nacional Autónoma de México, Centro de Investigaciones Interdisciplinarias em Ciencias y Humanidades.

Meo, A. (1995). Mapa institucional y políticas públicas destinados a mujeres "menores" vulneradas. Argentina. Delito y sociedad. Revista de Ciencias Sociales, (6-7), 131-142

Oliva, A. (2007). Desarrollo cerebral y asunción de riesgos durante la adolescencia. Apuntes de Psicología 25(3), 239-254.

Pérez islas, J. A., Valdez M. E Suárez, M. (coord.) (2008). Teorías sobre la juventud. Las miradas de los clásicos. Ciudad de México: IISUE, Miguel ángel Purrúa, UNAM.

Reguillo, R. (2010). Emergencia de Culturas Juveniles. Enciclopedia de Sociología y comunicación. Ciudad de México: Cultura libre.

Saraví, G. (2009). Transiciones vulnerables. Juventud, desigualdad y exclusión en México. Ciudad de México: CIESAS.

Urteaga, M. (1993). Identidad y jóvenes urbanos. Estudios Sociológicos, 11(32), 555-568.

Vasconcelos, R. (2012). Avances y retrocesos de la justicia penal para adolescentes. Ciudad de México: UNICEF.

Vasconcelos, R. (2009). La justicia para adolescentes en México. Análisis de las leyes estatales. Ciudad de México: UNICEF-UNAM.

Valenzuela, M. (2009) El futuro ya se fue. Socioantropología de l@s en jóvenes. Ciudad de México: COLEF. 